\title{
Wing Geometry as a Tool for Studying the Lutzomyia longipalpis (Diptera: Psychodidae) Complex
}

\author{
J De la Riva/ ${ }^{+}$, F Le Pont*, V Ali**, A Matias, S Mollinedo, JP Dujardin
}

\author{
INLASA, CP M-10019, Rafael Zubieta 1889, La Paz, Bolivia *UMR IRD-CNRS 9926, Montpellier, France \\ **UMSA, La Paz, Bolivia
}

\begin{abstract}
Toro Toro $(T)$ and Yungas $(Y)$ have been described as genetically well differentiated populations of the Lutzomyia longipalpis (Lutz \& Neiva, 1912) complex in Bolivia. Here we use geometric morphometrics to compare samples from these populations and new populations (Bolivia and Nicaragua), representing distant geographical origins, qualitative morphological variation ("one-spot" or "two-spots" phenotypes), ecologically distinct traits (peridomestic and silvatic populations), and possibly different epidemiological roles (transmitting or nor transmitting Leishmania chagasi). The Nicaragua $(N)$ (Somotillo) sample was "one-spot" phenotype and a possible peridomestic vector. The Bolivian sample of the Y was also "one-spot" phenotype and a demonstrated peridomestic vector of visceral leishmaniasis $(V L)$. The three remaining samples were silvatic, "two-spots" phenotypes. Two of them (Uyuni and T) were collected in the highlands of Bolivian where VL never has been reported. The last one (Robore, $R$ ) came from the lowlands of Bolivia, where human cases of VL are sporadically reported. The decomposition of metric variation into size and shape by geometric morphometric techniques suggests the existence of two groups $(N / Y / R$, and U/T). Several arguments indicate that such subdivision of Lu. longipalpis could correspond to different evolutionary units.
\end{abstract}

Key words: Lutzomyia longipalpis - geometric morphometrics - landmarks - centroid size - shape components Leishmania chagasi - visceral leishmaniasis

A high variability in Lutzomyia longipalpis (Lutz \& Neiva 1912) (Diptera: Psychodidae: Phlebotominae), vector of Leishmania chagasi, has been described at morphological and evolutionary levels. Morphologically, the most significant observation is the existence of "one-spot" and "twospots" phenotypes (Mangabeira 1969). This male trait corresponds to the occurrence of sexual pheromone glands (Lane \& Ward 1984). Evolutionarily Lu. longipalpis has been characterized as a complex of species. This was deduced from the existence of different sexual pheromones, not necessarily corresponding to the number of abdominal spots (Lane et al. 1985), and from hybridization and isoenzyme studies (Lanzaro et al. 1993, Lampo et al. 1999). These latter techniques allowed the recognition of three different biological species distributed in Colombia, Brazil and Costa Rica (Lanzaro et al.

\footnotetext{
This work has benefited from international collaboration through the Institut de Recherches pour le Developpement, Paris, France.

${ }^{+}$Corresponding author. Fax: +591-2-225280. E-mail: jascemineriv@mixmail.com

Received 17 July 2000

Accepted 23 August 2001
}

1993), and recently, the detection in Venezuela of two cryptic species occurring in sympatry (Lampo et al. 1999). In samples from Brazil, two isoenzyme comparisons suggested that $\mathrm{Lu}$. longipalpis is a single, but genetically heterogeneous, polymorphic species (Mukhopadhyay et al. 1998, Mutebi et al. 1999, Azevedo et al. 2000).

In Bolivia the "one-spot" phenotype of $L u$. longipalpis, vector of canine and human visceral leishmaniasis, is currently found in domestic and peridomestic environment of the Yungas, Y (Department of La Paz) (Le Pont \& Desjeux 1985). The "two-spots" phenotypes are described at the entrance of caves (Chiflonkaka, Humajalanta) at Toro Toro, $\mathrm{T}$ (Department of Potosi), a place where visceral leishmaniasis (VL) does not occur (Le Pont et al. 1989). Recently, other wild caught "two-spots" phenotypes were found at Uyuni, U (Department of Sucre, Bolivia), where VL is not reported, and at Robore, R (Department of Santa Cruz, Bolivia), a semiarid region where VL is sporadically reported.

A previous isoenzyme and metric comparison among Bolivian field populations of $\mathrm{Lu}$. longipalpis indicated a distinct population at T; it has a "twospots" phenotype showing consistent Nei's standard genetic distance (0.081) from the peridomestic, "one-spot" populations of the Y (Dujardin et al. 1997). 
Here we use geometric morphometrics to compare samples from these populations and new populations, notably the two new "two-spots" samples discovered in Bolivia (U and R).

\section{MATERIALS AND METHODS}

Insects (Fig. 1) - In total, 116 wings of male $L u$. longipalpis were examined (Table I): 26 from $\mathrm{N}$ (Somotillo, 220 masl, $\mathrm{n}=26$ ) and 90 from Bolivia. In Bolivia, captures were performed at high altitudes in the Departments of Sucre (U, at 2,000 masl, $n=$ 19) and Potosi (T, at 2,700 masl, $\mathrm{n}=20$ ), as well as in the Department of La Paz (Y, at 1500 masl, $n=23$ ). The remaining specimens came from a semiarid region in the lowlands of Bolivia bordering Brazil ( $R$, at 500 masl, $n=28$ ). All specimens were collected by light traps. Insects were mounted in Euparal medium according to the technique described by Abonnenc (1972).

Metric data (Fig. 2) - Wings are relatively rigid and well preserved structures even after dissection and are suitable structures for landmark data analysis in sand flies. Camera lucida drawings of the left and right wing were made on a microscope at a magnification that allowed maintenance of a consistent

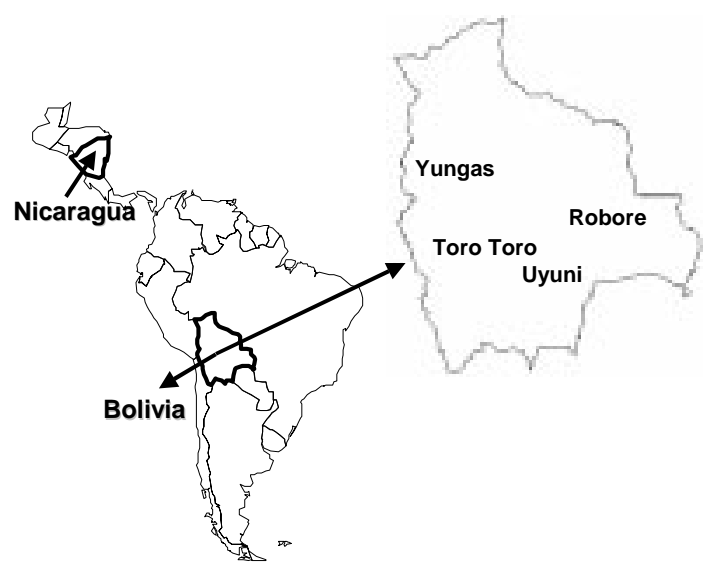

Fig 1: locations of the different populations of Lutzomyia longipalpis examined in this study. plane of focus to control distortion. On the distal part of the wing, we identified a total of 12 possible landmarks of "type I" (venation intersections) and one of "type II" (proximal extremity of R5) according to Bookstein's (1990) classification. To accord with relatively low sample sizes, our study was based on a subset of 5 landmarks (Bookstein 1996). The coordinates of landmarks were digitized using TPSDIG (version 1.5; Rohlf 1997).

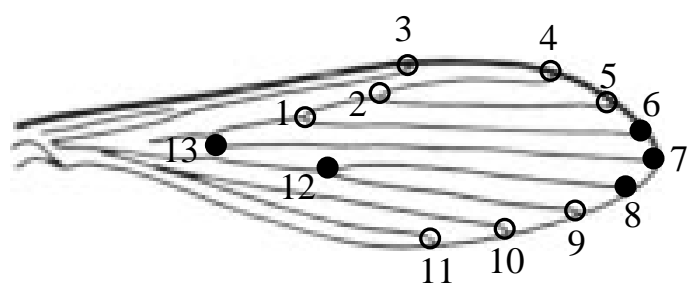

Fig 2: dorsal view of the male wing of Lutzomyia longipalpis. Thirteen possible landmarks corresponding to junction of veins except for the point 13 (proximal extremity of R5). The black circles indicate the landmarks used in this study.

Size variation - For comparing overall wing size among all groups, we used the isometric estimator known as "centroid size" (CTR). This is derived from coordinate data and is defined as the square root the sum of the squared distances between the specimen's landmarks and their arithmetic mean location. Standardizing size using CTR allows the computation of shape variables (see next paragraph). Because of the isometric nature of CTR, shape variables obtained may still include allometries (Baylac \& Daufresne 1996).

Shape variation - The raw landmark coordinates were first superimposed using a Generalized Procrustes superposition algorithm, whereby the sum of squared distances between each object and a reference configuration were iteratively minimized by translations and rigid rotations (Rohlf 1990). At each iteration the reference, which was taken as

TABLE I

Material examined

\begin{tabular}{llcc}
\hline Locality & Latitude & $\begin{array}{c}\text { Altitude } \\
\text { (masl) }\end{array}$ & $\begin{array}{r}\text { Number } \\
\text { of wings }\end{array}$ \\
\hline Nicaragua (N) & $13^{\circ} 02^{\prime} \mathrm{N}, 86^{\circ} 56^{\prime} \mathrm{W}$ & 200 & 26 \\
Yungas (Y) & $16^{\circ} 08^{\prime} \mathrm{S}, 67^{\circ} 42^{\prime} \mathrm{W}$ & 1,500 & 23 \\
Robore (R) & $18^{\circ} 20^{\prime} \mathrm{S}, 59^{\circ} 44^{\prime} \mathrm{W}$ & 800 & 28 \\
Uyuni (U) & $19^{\circ} 25^{\prime} \mathrm{S}, 64^{\circ} 48^{\prime} \mathrm{W}$ & 1,800 & 19 \\
Toro Toro (T) & $18^{\circ} 08^{\prime} \mathrm{S}, 65^{\circ} 45^{\prime} \mathrm{W}$ & 2,700 & 20 \\
\hline
\end{tabular}

N: (Group 1); Y: (Group 1, Bolivia); R: (Group 1, Bolivia); U: (Group 2, Bolivia); T: (Group 2, Bolivia) 
the mean configuration of the whole superimposed sample, was updated. All specimens were standardized to unit CTR. The partial warp (Generalized Procrustes superposition algorithm) scores of these superimposed data were used as shape variables (Rohlf 1993).

The Thin Plate Spline (TPS) interpolation function derived from the mean of the superimposed data was applied to a squared grid overlaying the mean landmark configuration to provide a direct and quantitative implementation of the D'ArcyThompson transformation grids (Bookstein 1991). We used this approach to illustrate shape changes along the first discriminant factor (the vertical axis of Fig. 3) to provide a visual representation of the shape variation indicated by this axis, including a "uniform" component corresponding to changes not altering the parallelisms of the grid and a "nonuniform" component indicated by local distortions of the grid.

Shape variables, i.e., both "uniform" and "nonuniform" components, were used as input for a discriminant (canonical variate) analysis. On the scatter plot of Fig. 3, we show only the first discriminant factor (the vertical axis) plotted against CTR. Reclassification based on all discriminant factors is presented in Table II, as well as in the Table III with Mahalanobis distances (Mahalanobis 1936) derived from the discriminant analysis.

Allometries - The relationships between the shape variables and any other variable (size, factor score, ecological variate, etc.) may be analyzed by multivariate regression analysis (Rohlf \& Marcus 1993).
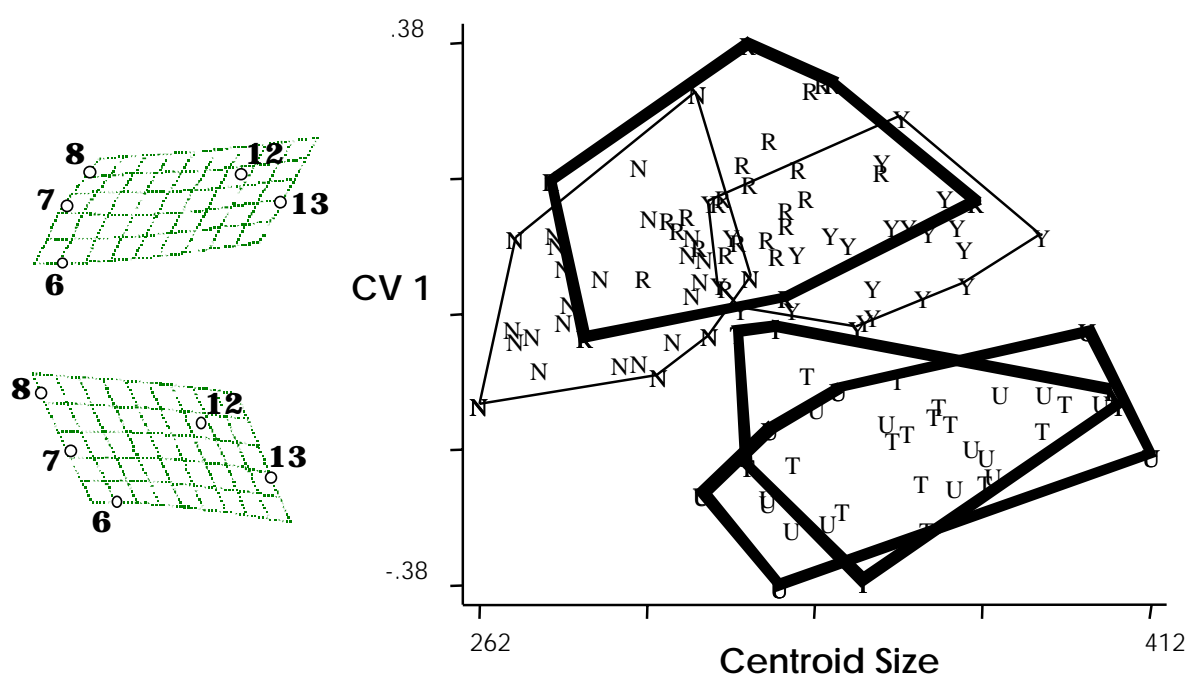

Fig 3: isometric size ("centroid size" or CTR) and shape variation among collections of male Lutzomia longipalpis from Nicaragua (N), Yungas (Y) and Robore (R) (Group 1, top polygons) and from Toro Toro (T), Uyuni (U) (Group 2, bottom polygons). Limits of each locality are shown by their convex hulls (polygons), bold lines for "two-spots" phenotypes ( $\mathrm{T}$, U, R). The horizontal axis represents CTR variation. The vertical axis (CV1) is the first discriminant factor derived from shape variables, expressing $82 \%$ of the total variation. To the left of this axis are thin-plate splines (amplified three times in order to make it more readable) showing the mean shapes of Group 1 and Group 2 as deformations from the grand mean.

TABLE II

Reclassification of samples

\begin{tabular}{ll}
\hline Landmarks & \multicolumn{1}{l}{ W6, W7, W8, W12, W13 } \\
\hline Shape variables $\quad$ x1, y1, x2, y2, u1, u2 & \\
\hline Correct Nicaragua (N) attribution & $76 \%(8 \%$ confounded with R, 8\% with Y, and 8\% with U) \\
Correct Yungas (Y) attribution & $70 \%(17 \%$ confounded with N, 13\% with R) \\
Correct Robore (R) attribution & $68 \%(14 \%$ confounded with N, 18\% with Y) \\
Correct Uyuni (U) attribution & $69 \%(26 \%$ confounded with T, 5\% with N) \\
Correct Toro Toro (T) attribution & $60 \%(30 \%$ confounded with U, 10\% with N)
\end{tabular}

W6, W7, W8, W12, W13: landmarks (see Fig. 2); x1, y1, x2, y2, uniX, uniY: shape variables, obtained from raw coordinates and processed by TPS relw (Rohlf); N: (Group 1); Y: (Group 1, Bolivia); R: (Group 1, Bolivia); U: (Group 2, Bolivia); T: (Group 2, Bolivia) 
TABLE III

Mahalanobis distances according to shape variation

\begin{tabular}{lccc}
\hline $\begin{array}{l}\text { Within- } \\
\text { group }\end{array}$ & Distances & $\begin{array}{c}\text { Between- } \\
\text { group }\end{array}$ & Distances \\
\hline $\mathrm{N}$ and R & 9.9 & $\mathrm{~N}$ and T & 14.1 \\
$\mathrm{~N}$ and Y & 6.4 & $\mathrm{~N}$ and U & 14.5 \\
$\mathrm{R}$ and Y & 6.4 & $\mathrm{R}$ and T & 20.0 \\
$\mathrm{~T}$ and U & 7.0 & $\mathrm{R}$ and U & 22.1 \\
& & Y and T & 16.1 \\
& & Y and U & 18.5
\end{tabular}

Mahalanobis distances derived from the discriminant analysis on shape variables. Based on partial warp scores (uniform + non-uniform) (see text for details). $\mathrm{N}$ : Nicaragua (Group 1); Y: Yungas (Group 1, Bolivia); R: Robore (Group 1, Bolivia); U: Uyuni (Group 2, Bolivia); T: Toro Toro (Group 2, Bolivia)

Regression parameters allow prediction (and visualization) of the shape changes in relation to the specified variable. We used this approach to model the allometric patterns associated with variation in CTR. Furthermore, the latter were compared statistically in a multivariate analysis of covariance (MANCOVA), with total shape variables as dependent variables, and locality, CTR and their interaction as in independent variables.

Software - Procrustes superimposition, TPS parameters, CTR and graphical output were obtained using TPSrelw (Rohlf 1998a) and TPSRegr (Rohlf 1998b) programs.

Statistical analyses were done using JMP ${ }^{\circledR}$ (SAS 1995) and STATA ${ }^{\circledR}$ (Computing resources 1992). They included discriminant analysis using the geographic localities as groups and multiple and simple linear regression of shape on size, as well as a MANCOVA for comparing allometric trends among localities.

\section{RESULTS}

Size variation (Fig. 3 ) - The $\mathrm{N}$ sample had the smallest wings, while the high localities (Y, U, T) had the largest. Intermediate between these two extremes were the wings from $\mathrm{R}$ in the lowlands of Bolivia. Although apparently not in obvious disagreement with elevation, this size variation did not show a significant correlation with altitude $(\mathrm{P}=0.09$, Mantel test).

Shape variation (Fig. 3) - The discriminant analysis derived from total shape (non-uniform and uniform components together) tended to separated two main groups along the first discriminant factor: the first one (Group 1) represented by N, Y and R, and the second one (Group 2) composed of $U$ and $\mathrm{T}$. The deformation grids along the (first) discriminant factor separating these two groups showed a strong uniform component (see Fig. 3). Multiple regression of shape variables on isometric size (CTR) was significant $(\mathrm{P}<0.003)$, however the explained variance of shape was relatively low (coefficient of determination was $16 \%$ ). The first discriminant factor, separating Group 1 and Group 2 on the basis of shape variation, was poorly $(6 \%)$ influenced by size (CTR).

Reclassification of specimens based on all discriminant factors resulted in the correct classification of $68 \%$ of the individuals to their respective locality of origin. A detailed examination of this classification (Table II) shows that this reclassification was almost perfect in relation to Group 1 and Group 2 (8\% of wrong classification, that is 5 specimens wrongly classified). Mahalanobis distances ranged from 6.4 to 22.1 , being systematically larger between localities belonging to different groups (Group 1, Group 2) than between localities within these two groups (Table II).

Allometric trends of the wing - The results of multivariate analysis of covariance on total geometric shape (with localities and size as independent variables, and their interaction) indicated no significant geographic differences in allometric trends: the relation of shape and size was similar for all localities.

\section{DISCUSSION}

Geometric variation of the wings of $L u$. longipalpis did not reveal large geographic subdivisions, as is frequent when examining morphometric variation. Neither did it separate ecological (peridomestic, silvatic) or phenotypic ("one-spot" and "two spots") characters. It is worth mentioning that the metric variation of the wings was not driven by the presence of "one-spot" and "twospots" morphs, supporting other studies reporting no genetic differences between the two morphs. Nevertheless, our analysis of wing shape variation revealed here two clusters, named hereafter as Group 1 and Group 2.

Group $1(\mathrm{~N}, \mathrm{Y}, \mathrm{R})$ is a composite assemblage of possible vector populations of $L u$. longipalpis including either silvatic, "two-spots" specimens (R) or peridomestic, "one-spot" specimens $(\mathrm{Y}, \mathrm{N}) \mathrm{com}$ ing from high $(\mathrm{Y})$ or low $(\mathrm{N}, \mathrm{R})$ altitudes. Group $2(\mathrm{~T}$, $\mathrm{U})$ was more homogenous, since these not too distant localities $(175 \mathrm{~km})$ were composed of "twospots" phenotypes, both of them from very high altitudes in Bolivia (T, U), living in silvatic conditions and of unknown, but probably of no, epidemiological significance.

These two groups were recognized mainly by shape differences. The way shape was "extracted" from metric variation (see Procrustean superposition, Material and Methods) did not exclude some allometric influence on its variation. That is, even 
when isometric size (CTR) has been controlled, differences in growth states could still be a significant cause of shape variation. The contribution of size variation to the total shape variation was $16 \%$. This influence on shape variation in Group 1 and Group 2 was lower $(6 \%, \mathrm{P}=0.006)$, as indirectly estimated by performing a simple linear regression of the first canonical factor (CV1, see Fig. 3) on CTR (Baylac \& Daufresne 1996, Klingenberg 1996).

The two groups could have different epidemiological importance. Group 1 is likely to contain active vectors of Le. chagasi. This has been demonstrated in the Y (Le Pont \& Desjeux 1985). It is speculated for N (Belli et al. 1999), and for R where VL is known to occur (Monteiro de Barros \& Rosenfeld 1942, Zuna et al. 1987). Group 2 is living in a geographic area where VL cases never have been reported. Although related to environmental variation (animal reservoir), the vectorial capacity is generally recognized as a genetic trait (Killick-Kendrick 1985, Pimenta et al. 1994). Two other, indirect arguments also supported the hypothesis of genetic differences separating Group 1 and Group 2.

The first argument is related to the nature of shape divergence. Indeed, our data does not support growth (size variation) as the main cause of the observed distinction between Group 1 and Group 2, except for a 6\% contribution (see above). Thus, other causes could be invoked such as adaptative or genetic ones.

The second argument which could be indicative of genetic differences rather than environmental ones was the lack of significant correlation between size and altitudes. As stated by Bergmann's rule (Atkinson 1994) - and as a long as it means correlation of size with temperature - such a correlation is expected to occur among local populations of the same species or among very closely related species. The observed discordance is an argument against simple intraspecific variation (Lane \& Fritz 1986, Marcondes et al. 1998, Dujardin et al. 1999, Dujardin \& Le Pont 2000).

Finally, it is worth mentioning that our results are in agreement with previous isoenzyme analysis on some of these populations estimating a consistent Nei's genetic distance (0.081) between the Y (Group 1 ) and the $\mathrm{T}$ (Group 2) populations but a considerably lower distance (ranging 0.000 to 0.002 ) within the Y population (Dujardin et al. 1997). Similarly, our metric distances estimated here (Mahalanobis distances) varied from 14 to 22 between groups, whereas the same estimation within groups gave values ranging from 6 to 10 .

Our results show the variation of the geometry of the wing of $L u$. longipalpis is in agreement with a genetically heterogeneous species in Bolivia.

It is thought that isomorphic species with vary- ing vectorial capacity may be responsible for the discontinuous distribution on VL (Mutebi et al. 1999). Between such cryptic species where apparently no reliable discrete anatomical attribute is diagnostic, molecular examination remains indispensable as a source of evidence (Bonnefoy et al. 1986, Lanzaro et al. 1993, Dujardin et al. 1997, Lampo et al. 1999). Karyotype has recently been proposed as an alternative (Huaizhi et al. 1999). As shown by our study, though, a role for a less expansive techniques such as morphometrics might be reclaimed.

\section{ACKNOWLEDGEMENTS}

To Dr D Slice, Depto of Ecology \& Evolution, State University of New York Stony Brook, and Dr R Andrade, Director of the INLASA (La Paz, Bolivia), for helping this investigation.

\section{REFERENCES}

Abonnenc E 1972. Les phlébotomes de la Région Ethiopienne (Diptera: Psychodidae). Mem ORSTOM 55: 1-284.

Atkinson D 1994. Temperature and organism size: biological law for ectotherms? Adv Ecol Res 25: 1-58.

Azevedo de ACR, Monteiro FA, Cabello PH, de Souza NA, Rosa-Freitas MG, Rangel EF 2000. Studies on populations of Lutzomyia longipalpis (Lutz \& Neiva 1912) (Diptera: Psychodidae: Phlebotominae) in Brazil. Mem Inst Oswaldo Cruz 95: 305-322.

Baylac M, Daufresne T 1996. Wing venation variability in Monarthropalpus buxi (Diptera: Cecidomyiidae) and the quaternary coevolution of box (Buxus sempervirens $L$.) and its midge. A geometrical morphometric analysis. In LF Marcus, M Corti, A Loy, $\mathrm{G}$ Naylor, DE Slice (eds), Advances in Morphometrics, NATO-ASI No. 284, Plenum Press, New York, p. 285-301.

Belli A, Garcia D, Palacios X, Rodriguez B, Valle S, Videa E, Tinoco E, Marin F, Harris E 1999. Widespread a typical cutaneous leishmaniasis caused by Leishmania (L.) chagasi in Nicaragua. Am J Trop Med Hyg 61: 380-385.

Bonnefoy S, Barnabe C, Tibayrenc M, Le Pont F, Dujardin JP, Desjeux P, Ayala FJ 1986. An isozymic study of Lutzomyia longipalpis (Diptera, Psychodidae), the vector of visceral leishmaniasis in the "Yungas" (Bolivia) Cah ORSTOM, sér Entomol Méd et Parasitol XXIV: 213-217.

Bookstein FL 1990. Introduction to methods for landmark data. In FJ Rohlf, FL Bookstein (eds), Proceedings of the Michigan Morphometrics Workshop, The University of Michigan Museum of Zoology, Special Publication 2, Ann Arbor, p. 216-225.

Bookstein FL 1991. Morphometric Tools for Landmark Data: Geometry and Biology, Cambridge University Press, Cambridge, 435 pp.

Bookstein FL 1996. Combining the tools of geometric morphometrics. In LF Marcus, M Corti, A Loy, GJP Naylor, D Slice (eds), Advances in Morphometrics, Proceedings of the 1993 NATO-ASI on morphometrics, Plenum Publ., NATO ASI, ser. A, life Sicences, New York, p. 131-151. 
Computing Resource Center 1992. Stata Reference Manual: Release 3, 5th ed., Computing Resource Center, Santa Monica.

Dujardin JP, Le Pont F 2000. Morphometrics of a sand fly subspecies: L. carrerai thula. Life Sciences 323 : 273-279.

Dujardin JP, Le Pont F, Martinez E 1999. Quantitative morphological evidence for incipient species within Lutzomyia quinquefer (Diptera:Psychodidae). Mem Inst Oswaldo Cruz 94: 829-836.

Dujardin JP, Torrez E, Le Pont F, Hervas D 1997. Isozymic and metric variation in the Lutzomyia longipalpis complex. Med Vet Entomol 1: 394-400.

Huaizhi Yin, Mutebi JP, Marriott S, Lanzaro GC 1999. Metaphase karyotype and G-banding in sandflies of the Lutzomyia longipalpis complex. Med Vet Entomol 13: $72-77$.

Killick-Kendrick R 1985. Some epidemiological consequences of the evolutionary fit between Leishmaniae and their Phlebotominae vectors. Bull Soc Path Ex 78: 747-755.

Klingenberg CP 1996. Multivariate allometry. In LF Marcus, M Corti, A Loy, JGP Naylor, D Slice (eds) Advances in Morphometrics, Proceedings of the 1993 NATO-ASI on Morphometrics, Plenum Press, NATO ASI, ser A., Life Sciences, New York, p. 23-49.

Lampo M, Torgerson D, Marquez LM, Rinaldi M, Garcia CZ, Arab A 1999. Ocurrence of sibling species of Lutzomyia longipalpis (Diptera: Psychodidae) in Venezuela: first evidence from reproductively isolated sympatric populations. Am J Trop Med Hyg 61: 1004-1009.

Lane R, Ward R 1984. The morphology and possible function of abdominal patches in males of the two forms of the leishmaniasis vector Lutzomyia longipalpis. Cah ORSTOM, sér Entomol Méd et Parasitol XXII: 245-249.

Lane R, Phillips A, Molyneux D, Drocten G, Ward R 1985. Chemical analyses of the abdominal glands of two forms of Lutzomyia longipalpis: site of a possible sex pheromone? Ann Trop Med Parasitol 79: 225-229.

Lane RP, Fritz G 1986. The differentiation of the leishmaniasis vector Phlebotomus papatasi from the suspected vector $P$. bergeroti (Diptera:Phlebotominae). Systematic Ecology Oxford 11: 439-445.

Lanzaro G, Ostrovska K, Herrero M, lawyer P, Warburg A 1993. Lutzomyia longipalpis is a species complex: genetic divergence and interspecific hybrid sterility among three populations. Am J Trop Med Hyg 48: 839-847.

Le Pont F, Desjeux P 1985. Leishmaniasis in Bolivia. I. Lutzomyia longipalpis (Lutz \& Neiva 1912) as the vector of visceral leishmaniasis in Los Yungas. Trans $R$ Soc Trop Med Hyg 79: 227-231.

Le Pont F, Mouchet J, Desjeux P 1989. Phlebotomes de Bolivie. VII. Répartition des deux morphotypes du phlébotome Lutzomyia longipalpis (Lutz \& Neiva 1912) (Diptera: Psychodidae) dans le piémont andin de Bolivie. Mem Inst Oswaldo Cruz 93: 363-364.

Mahalanobis PC 1936. On the generalized distance in statistics. Proc Natl Inst Sci India 2: 49-55.
Mangabeira 1969. Sobre a sistematica e biologia dos Phlebotomus do Ceará. Rev Malariol Doen Trop 21: 3-26.

Marcondes CB, Lozovei AL, Galati EAB, Taniguchi HH 1998. The usefulness of Bergmann's rule for the distinction of members of Lutzomyia intermedia species complex (Diptera, Psychodidae, Phlebotominae). Mem Inst Oswaldo Cruz 93: 363-364.

Monteiro de Barros O, Rosenfeld G 1942. Leishmaniose visceral americana, um caso da Bolivia. Rev Clín de S. Paulo XI: 5-17.

Mukhopadhyay J, Ghosh K, Rangel E, Munstermann L 1998. Genetic variability in biochemical characters of Brazilian field populations of the Leishmania vector, Lutzomyia longipalpis (Diptera, Psychodidae). Am J Trop Med Hyg 59: 893-901.

Mutebi JP, Alexander B. Sherlock I, Wellington J, Souza AA, Shaw J, Rangel EF, Lanzaro GC 1999. Breeding structure of the sand fly Lutzomyia longipalpis (Lutz \& Neiva) in Brazil. Am J Trop Med Hyg 61: 149-57.

Pimenta PFP, Saraiva EMB, Rowton E, Modi GB, Garraway LA, Beverley SM, Turco SJ, Sacks DL, 1994. Evidence that the vectorial competence of phlebotomine sand flies for different species of Leishmania is controlled by structural polymorphism in the surface lipophosphoglycan. Proc Natl Acad Sci USA 91: 9155-9159.

Rohlf FJ 1990. Rotational fit (Procrustes) methods. In FJ Rohlf, FL Bookstein (eds), Proceedings of the Michigan Morphometrics Workshop, University of Michigan Museums, Ann Arbor, p. 227-236.

Rohlf FJ 1993. Relative warp analysis and an example of its application to mosquito wings. In LF Marcus, E Bello, A Garcia-Valdecasas (eds), Contribution of Morphometrics, Monografias del Museo Nacional de Ciencias Naturales 8, Madrid, p. 131-159.

Rohlf FJ 1997. TPSDIG for Windows version 1.5. Department of Ecology and Evolution, State University of New York, Stony Book, (available by ftp from life.Bio.SUNYSB.edu/MORPHMET).

Rohlf FJ 1998a. Tps Relw for Windows v. 1.17, Thin Plate Spline Relative Warps Analysis. Department of Ecology and Evolution, State University of New York, Stony Book (available by ftp from life.Bio.SUNYSB.edu/MORPHMET).

Rohlf FJ 1998b. TPSREGR for Windows version 1.15. Department of Ecology and Evolution, State University of New York, Stony Book (available by ftp from life.Bio.SUNYSB.edu/MORPHMET).

Rohlf FJ, Marcus LF 1993. A revolution in morphometrics. TREE 8: 129-132.

SAS Institute Inc.1995. JMP® Statistics and Graphics Guide, Version 3.1, SAS Campus Drive, Cary, NC, 592 pp.

Sokal RR, Rohlf JF 1995. Biometry: the Principles and Practice of Statistics in Biological Research, 3rd ed., WH Freeman and Company, New York, 887 pp.

Zuna H, Ortiz de la Ferte B, Cardozo L, Portales J, Urjel R, Katimi A, Mendez W 1987. Descripción de un caso de leishmaniasis visceral (Kala azar) proveniente del Nor-Este del departamento de Santa Cruz (Provincia Angel Sandoval) Bolivia. Bol Cient CENETROP XIV: 44-49. 